one's teaching and provides a toolbox of processes.

Part three of this book is concerned with more detailed and theoretical aspects concerning common issues in teaching and learning. Coming on the back of the more practical part of the book, the core educational theories that it presents are made to feel relevant and interesting. It begins with a chapter on curriculum and then moves on to assessment and evaluation.

The book is concluded with a useful appendix which gives a glossary of medical education terms and then recommended resources for teaching.

This is a concise book that would be invaluable for anyone wishing to expand their knowledge and practical skills in the field of medical education. Although based on medical student teaching, the information it contains would be useful for any clinical teaching setting. The second part of the book provides a valuable resource that one can dip into when planning teaching sessions. It does just what is says on the tin-a straightforward, practical guide about day-to-day teaching and learning in busy hospitals.

C Turner

\section{A clinical guide to inherited metabolic diseases}

Edited by J T R Clarke. Cambridge University Press, 2006, softcover, pp 323, £40 (US\$75 (approx.), €60 (approx.)). ISBN 0521614996

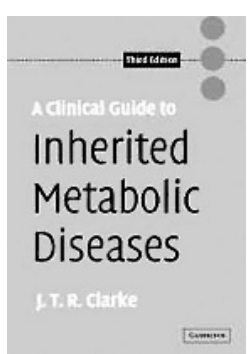

"Inherited"

and

"metabolic diseases"two phrases that send chills down the spine of a junior doctor. These two words represent endless hours one spent learning al about the mutations, the enzymes and coenzymes, the substrate deficiencies, and all those complex biochemical reactions in medical school, and still failed to grasp the complexity of the problem.

In this book, Dr Clarke has made an effort to provide a clear and concise overview of how to go about diagnosing and treating inherited metabolic diseases.

The book takes off in an easy, smooth fashion, with an introduction to basics of metabolic diseases. It starts with a historic perspective and then goes onto explain the basic principles of deranged metabolism.

The rest of the book is organised into chapters according to the most prominent presenting complaint of patients with metabolic diseases: neuro, hepatic, cardiac, metabolic acidosis, dysmorphism, and acute illness in the newborn. Each chapter provides an in depth analysis of the presenting complaint. Then the chapters go on to outline the diagnosis and management of these conditions. Dr Clarke has managed to achieve a good balance between being simple, yet providing enough detailed information about complex conditions. Unlike other textbooks in the market, which divide their chapters into urea cycle defects, glycogen storage disorders, and so on, this book by Dr Clarke is problem based and moves from presenting complaint to diagnosis and treatment. The book is formatted to appeal to both the novice reader and experienced clinician.

The chapter on screening touches on both ethical and clinical controversies associated with screening for metabolic diseases in the newborn. The chapters on laboratory investigations and recent treatment options offer practical advice to clinicians who see patients with metabolic diseases rarely.

There are, however, some areas where the book disappoints you. The cover page is not very attractive. It does not make you automatically want to reach out for the book on a library shelf. The book does not contain any case reports or anecdotal experiences which would have made interesting reading. It is written in a monologue, failing to capture the imagination of the reader.

On the whole, a very useful book for quick reference to the management of metabolic problems.

M Madhava

\section{A clinician's handbook of child and adolscent psychiatry}

Edited by Christopher Gillberg, Richard Harrington, Hans-Christoph Steinhausen. Cambridge University Press, 2006, £65.00 (US\$120 (approx.); €95 (approx.)), pp 725, hardback. ISBN 0-521-81936-9

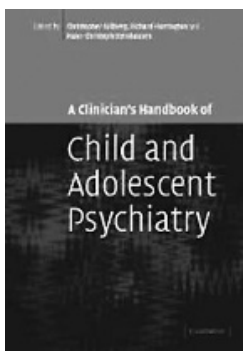

I was very excited when this book arrived; in fact I hadn't heard about this book before, although it is one of few textbooks of child and adolescent psychiatry, and was intrigued to find out how it compared to existing textbooks.

On initial approach the layout looked very user-friendly, with chapters spanning over the whole of child and adolescent psychopathology, but also including sleep disorders, elimination disorders, and gender identity disorders.

I was also positively impressed by the aims of the editors, including wanting to summarise the most relevant scientific knowledge about each disorder in a format useful for clinicians.

Each chapter focuses on a particular disorder or group of disorders. The layout of each chapter is in fact very simple and easy to use, with definition and classification of each disorder at the beginning, a section on epidemiology, the clinical picture, a brief overview of the aetiology, and a larger section on treatment. Each chapter has a very useful appendix, mostly including a list of commonly used rating scales, or the scales themselves, for the relevant disorder. However, some appendixes were better than others. I was not impressed by the appendix to the OCD chapter, while I was by the useful material at the end of the eating disorders chapter. I liked the diagrams and treatment algorithms that are used throughout the book.

There are two very useful chapters on specific developmental disorders of speech and language and "reading and other learning disorders". There is also a very useful chapter on brain disorders, tapping into the overlap of child neurology and psychiatry.

I particularly liked the chapters on hyperkinetic disorder, conduct disorder, eating disorders, and the chapter on gender identity disorders, not often included in the taxonomy of child psychiatry.

I was surprised not to find a chapter on deliberate self-harm, given the prevalence of this among adolescents.

This is a very good book; it is well written by experts in the field. It achieves its aims in wanting to be useful and easy-to-read for clinicians. I can see its place in the bookshelves of paediatricians, child and adolescent psychiatrists, as well as other professionals working with children and adolescents. It is a good reference book, given that it is very practical and user-friendly. It is easy to read and the information is well laid out, so that one can pick and read what one is interested in.

N Micali

\section{CORRECTION}

H Bauchner. Atoms (Arch Dis Child 2006; 91(7):i). The dosage of dexamethasone should have been stated as $0.15 \mathrm{mg} / \mathrm{kg}$ (and not $15 \mathrm{mg} / \mathrm{kg}$ as stated in the July Atoms).

Pre-published book reviews

Book reviews that have been accepted for publication but have not yet been published in the print journal can be viewed online at http://adc.bmijournals.com/misc/bookreviews.shtml 